\title{
Percepções das Discentes dos Cursos de TI Sobre as Subáreas da Computação
}

\author{
Vinicius H. S. Gomes, Ivonaldo D. Araújo, Izabelly S. Morais \\ Departamento de Ciências Exatas (DCX) - Universidade Federal da Paraíba (UFPB) \\ CEP - 58.297-000 - Rio Tinto - PB - Brasil \\ \{vinicius.henrique, ivonaldo.duarte,izabelly.soares\}@dcx.ufpb.br
}

\begin{abstract}
This paper presents a research conducted with Computer Science (LCC) and Bachelor of Information Systems (BSI) students from the Federal University of Paraiba - Campus IV, with the objective of assessing the level of information about the computational subareas. interest levels to learn more about these subareas. The research was conducted through an online questionnaire and we obtained a satisfactory preliminary results, with proposal for future work.
\end{abstract}

Resumo. Este artigo apresenta uma pesquisa realizada com estudantes de Licenciatura em Ciência da Computação (LCC) e Bacharel em Sistemas de Informação (BSI) da Universidade Federal da Paraíba - Campus IV, com o objetivo de aferir o nível de informação sobre as subáreas de computação e os níveis de interesse para saber mais sobre essas subáreas. A pesquisa foi realizada por meio de questionário online e obtivemos um resultado preliminar satisfatório, com proposta para trabalhos futuros.

\section{Introdução}

É comum listarmos grandes marcos tecnológicos que foram sendo desenvolvidos ao longo dos anos. Porém, na maioria das vezes, os nomes listados trazem destaques masculinos. Fato este, que não se limita apenas a área tecnológica, mas também a que chamamos de exatas, que envolvem raciocínio lógico, matemática, dentre outras. Dentro deste contexto, é importante ressaltarmos que as mulheres contribuíram e ainda se fazem atuante em grandes descobertas na história da sociedade. Apesar do fato histórico cultural, nomes como Ada Lovelace, Grace Hopper e as programadoras do ENIAC $^{1}$, um grupo de seis mulheres que foram as primeiras computers [Schwartz et al 2006], são relevantes e representam o protagonismo feminino no ramo da ciência, especialmente, na história da computação.

Entretanto, é fato que ainda existe um espaço desigual entre homens e mulheres, essa disparidade persiste tanto no âmbito acadêmico, por exemplo, nos cursos de Tecnologia de Informação (TI) onde a quantidade de mulheres é mínima em relação ao gênero oposto, quanto no ambiente profissional. De acordo com os dados do Instituto Nacional de Estudos e Pesquisas Educacionais (INEP) vinculado ao Ministério da Educação (MEC), no Brasil o número de cursos de computação cresceram 586\% ao

\footnotetext{
${ }^{1}$ http://eniacprogrammers.org
} 
longo dos últimos 24 anos. Tendo em vista que o percentual de mulheres matriculadas nesses cursos passaram de 34,8\% para 15,5\% [Andrade 2019].

Mas, por que a participação feminina na tecnologia é importante? Esse movimento não se relaciona apenas à questão da diversidade e da quebra de mitos construídos sobre as mulheres na tecnologia. Vai além disso, quando a sua inserção na área se relaciona com o poder de influência que é exercido sobre outras gerações [Lima 2013]. Entender sobre os desafios de promover a maior participação feminina, possibilita uma real contribuição a fim de tentar recuperar o histórico inicial das mulheres na ciência, especificamente, na computação. Nesse sentido, há uma grande necessidade de maior inserção de mulheres no campo de Tecnologia da Informação (TI), para que um dia consigamos diminuir essa desigualdade e ampliar a diversidade de gênero no meio acadêmico e no mercado de trabalho.

Mediante à esta tentativa alguns desafios são encontrados, tais como descobrir e entender de onde surge a motivação para ingressar no mundo da computação. Nesse ponto de vista, há dois tipos de motivações ${ }^{2}$ que podemos considerar: primeiro, a motivação intrínseca, que depende do próprio indivíduo e está ligado às prioridades, valores e desejos internos. Segundo, a motivação extrínseca, que é provocada pelo ambiente e muito importante, por exemplo, no espaço corporativo para manter os funcionários empenhados e envolvidos com a empresa [SBIE 2017].

No Brasil, qualquer estudo sobre pesquisa em computação precisa levar em conta as atividades da Sociedade Brasileira de Computação (SBC) [Medeiros 2011]. Sendo assim, a SBC ramifica a computação em 27 Comissões Especiais ${ }^{3}$ (CEs), algumas delas exprimem relação a mais de uma Grande Área (GA), cada CE é caracterizada como subárea da computação [SBC 2019]. Apesar de alguns cursos de computação discorrer de tais subáreas, é comumente que nem todos os estudantes de TI alcancem da mesma forma as informações a respeito de todas as subáreas, com o propósito de sua percepção ser agregada para além das áreas de desenvolvimento e programação de códigos.

Desta forma, o presente artigo traz uma pesquisa preliminar efetuada com as discentes de Licenciatura em Ciências da Computação (LCC) e Bacharelado em Sistemas de Informação (BSI), mapeada na Universidade Federal da Paraíba, Campus IV - Rio Tinto, localizada no litoral norte do estado. O objetivo é o de compreender o nível de conhecimento e interesse em estudar as subáreas da computação, além disso, compreender a motivação que gerou esse interesse. Para esse êxito, é feito associação com os conceitos de motivação intrínseca e/ou extrínseca.

Este trabalho está dividido em cinco seções além desta introdução, e serão conduzidas por tópicos, decorrentes da seção 2 que discute alguns trabalhos relacionados. Seção 3, onde trata sobre a metodologia utilizada para obtenção dos dados e como foram executados os procedimentos. A seção 4, intitulada resultados e discussão, abrange a percepção de todas as informações alcançadas, além das associações com as definições de motivação intrínseca e extrínseca. Por fim, na seção 5, apresentamos as considerações finais da pesquisa e propostas para trabalhos futuros.

\footnotetext{
${ }^{2}$ https://www.sbie.com.br/blog/entenda-diferenca-entre-motivacao-intrinseca-e-extrinseca/

${ }^{3}$ http://www.sbc.org.br/403-comissoes-especiais
} 
VIII Congresso Brasileiro de Informática na Educação (CBIE 2019)

Anais dos Workshops do VIII Congresso Brasileiro de Informática na Educação (WCBIE 2019)

\section{Trabalhos Relacionados}

A importância da temática, ressalta a necessidade de trabalhos que busquem debater e trazer informações sobre este cenário no nosso país. Para isso, os trabalhos relacionados foram selecionados nos anais dos principais eventos, tais como: os anais do Women in Information Technology (WIT), que é uma iniciativa da SBC para discutir os assuntos relacionados a questões de gênero e a Tecnologia de Informação (TI) no Brasil. Com isso, a partir do anal de 2017, foram apurados os trabalhos que envolviam o gênero feminino com as subáreas da computação.

Um dos trabalhos encontrados é o de Figueiredo [et. al. 2017], que consistiu em uma pesquisa realizada com as discentes de ensino médio de uma escola do interior do estado de Mato Grosso, com o objetivo de medir o nível de informação acerca das subáreas da computação. Outro trabalho relacionado é o de Duarte [et. al. 2019], que buscou caracterizar a participação feminina nas subáreas da computação, durante os comitês do programa dos principais simpósios do SBC no período de 2011 a 2018.

Sumarizando a análise dos trabalhos relacionados, o primeiro teve uma perspectiva das discentes do ensino médio, fazendo um estudo com os conhecimentos prévio de cada participante. De acordo com os resultados, as jovens tendem seu interesse por subáreas lúdicas e mais difundidas pela mídia, se encaixando na definição de motivação extrínseca, abordada no presente estudo. Já no segundo trabalho relacionado, levantaram como principal resultado a maior participação de mulheres em áreas mais interdisciplinares, relacionadas à aplicação da computação ou com aspecto social claro, no que distingue das áreas elencadas pelas mulheres do estudo vigente.

O presente artigo se diferencia dos trabalhos relacionados pelo fato da pesquisa focar nas opiniões das discentes do ensino superior e que já possuem algum contato com a computação. Trazendo destaque, sobretudo, na importância de descobrir o que as motivam nas áreas da computação. Pois consideramos que a busca da compreensão pelas razões das quais a inspiram, são fatores de direcionamento e permanência tanto durante quanto depois da graduação.

\section{Metodologia}

A pesquisa foi efetuada com as mulheres dos cursos de LCC e BSI da Universidade Federal da Paraíba, Campus IV - Rio Tinto, localizada no litoral norte do estado. Foi aplicada através do envio de um formulário ao email institucional de cada estudante de ambos os cursos, podendo ser respondido tanto em dispositivos desktop como mobile.

Com a intenção de entender a proporção das discentes em relação ao total de estudantes no semestre vigente 2019.1 (de acordo com calendário acadêmico), foram exercidas consultas no Sistema Integrado de Gestão de Atividades Acadêmicas (SIGAA), obtendo resultado de 275 alunos ativos no curso de LCC e 180 no curso de BSI. Deste total de alunos disponíveis, pôde-se extrair a quantidade de discentes ativas em ambos os cursos, disseminadas em 35 mulheres no curso de LCC e 19 em BSI. Representando, respectivamente, o percentual de $12,7 \%$ de estudantes femininas no curso de licenciatura e 10,5\% no bacharelado. Das discentes participantes desta pesquisa, 14 atenderam ao questionário, identificadas como sete discentes de LCC e sete 
VIII Congresso Brasileiro de Informática na Educação (CBIE 2019)

Anais dos Workshops do VIII Congresso Brasileiro de Informática na Educação (WCBIE 2019)

de BSI. Foi definido um conjunto de ações para a metodologia, que pode ser melhor abstraída na Figura 1 a seguir.

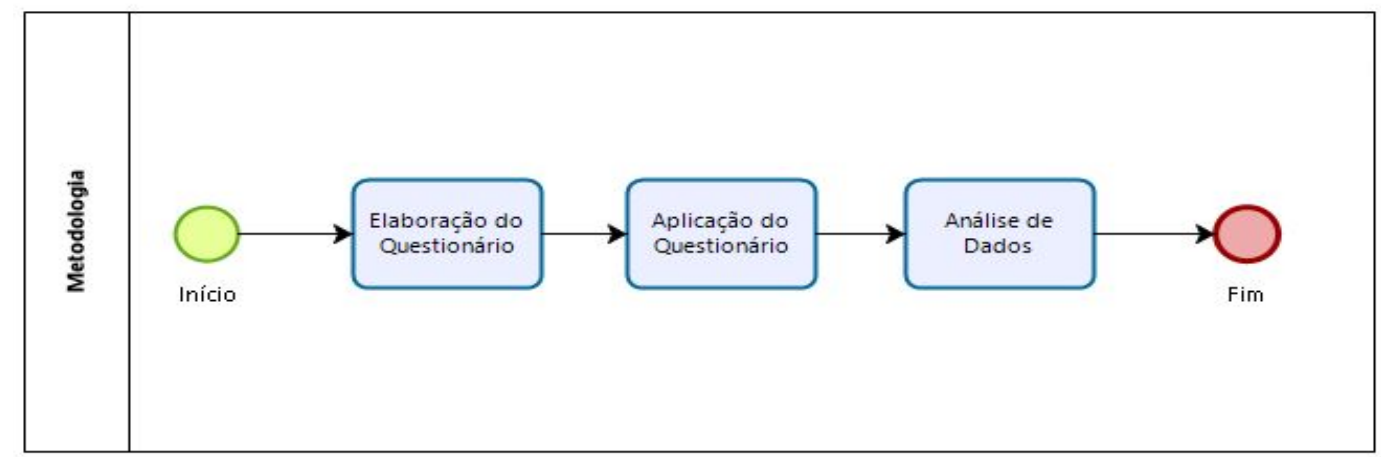

Figura 1. Fluxo metodológico

A primeira etapa do trabalho consistiu na elaboração de um questionário de roteiro estruturado, contendo cinco perguntas que integram a concretização do objeto de estudo. Para a coleta dos dados utilizou-se de um formulário ${ }^{4}$ online (Google Forms) disponibilizado em português, que constrói o perfil das respondentes quais sejam nome e período do curso, motivações gerais e específicas. A segunda etapa visou a aplicação deste formulário, que foi lançado ao email institucional de cada estudante do departamento de Ciências Exatas (DCX). Por último, completamos o fluxo com a análise dos dados, no qual remete a identificação das subáreas mais conhecidas e menos conhecidas e as ditas como mais interessantes e menos interessantes pelas discentes.

As perguntas foram organizadas por definição funil, consistindo de perguntas gerais com o objetivo de contextualizar no início e em seguida direcionar as discentes a perguntas mais específicas, incluindo questões objetivas e subjetivas. As perguntas estão indicadas numericamente e tipificadas em opinião e valores (3 e 5), conhecimento (4), contexto e demografia (1 e 2). Estruturou-se da seguinte maneira: (1) Qual o seu curso?; (2) Em qual período se encontra?; (3) Que motivação fez você escolher a área de TI?; (4) Continha as 27 subáreas da Computação listadas em formato de grade e as seguintes opções para resposta: "Desconheço e tenho interesse em estudar", "Desconheço e NÃ̃O tenho interesse em estudar", "Conheço e tenho interesse em estudar", "Conheço e NÃO tenho interesse em estudar", e "Não sei estimar meu interesse"; (5) Destas 27 subáreas listadas acima, como você definiria o motivo de interesse? Por exemplo, foi uma descoberta dentro do curso (disciplinas, professores, projetos, etc) ou uma motivação interna sua?.

Como parte final da metodologia, utilizou-se da técnica de análise de conteúdo que segundo Bardin [2016] se constitui em uma metodologia de pesquisa usada para descrever e interpretar o conteúdo de documentos e textos, com o objetivo de reinterpretar as respostas para que se alcance uma compreensão mais refinada de seus significados. Ela se restringe nos seguintes passos: pré-análise, exploração do material e tratamento dos resultados.

\footnotetext{
${ }^{4}$ https://forms.gle/7JYrmjfNCgPR6cwv8
} 
Seguindo o método adotado, inicialmente realizou-se a pré-análise, onde ocorre o primeiro contato com as informações coletadas e tem por objetivo a organização dos dados. Nesta etapa, ocorreu a análise dos dados das questões subjetivas, a fim de padronizar a escrita de algumas respostas. Sendo assim, as respostas das perguntas (3) e (5) foram padronizadas, pois algumas indicavam a mesma ideia, mas com escritas diferentes.

Logo depois, na etapa de exploração do material, cumpriu-se a agregação dos dados nas categorias das Grandes Áreas (GAs), baseadas na SBC, de forma que se pudesse alcançar o objetivo da pesquisa. Esta triangulação dos dados, que segundo [Tuzzo and Braga 2016] é a "forma de integrar diferentes perspectivas no fenômeno em estudo", se deu em selecionar as variáveis de respostas comuns às participantes e distribuí-las nas GAs representativas, a fim de identificar qual GA mais se aproxima do interesse das mulheres.

$\mathrm{Na}$ última fase é possível "propor inferências e sugerir hipóteses, sobre o objetivo da pesquisa ou que digam respeito a outras descobertas" [Bardin 2016], referente ao tratamento dos resultados, as informações foram tratadas de maneira considerável, e com base nas operações estatísticas conseguimos gerar um gráfico e uma tabela contendo os resultados concisos, além disto, a percepção abrangente pelas GAs.

\subsection{Motivação Intrínseca e Extrínseca}

Visando entender a motivação para o interesse em determinada área, replicada pelas próprias melhores, buscou-se exprimir conforme o significado de motivação intrínseca e extrínseca. Pois entendemos que a busca da compreensão pelas razões das quais as influenciam, são fatores de direcionamento e permanência no que diz respeito ao futuro profissional na área.

Para Bergamini [2003], a motivação é objeto de considerações diferentes entre si. Pois nem sempre mais de um indivíduo, embora esteja dentro do mesmo contexto, consegue gerar o mesmo interesse. Os conceitos de motivação enfatizam um ou a combinação de três tipos de variáveis: "1- determinantes ambientais; 2- forças internas (necessidade, desejo, emoção, impulso, instinto, vontade, propósito, etc.); 3-incentivo, alvo ou objeto que atrai ou repele o organismo." [Witter and Lomonaco 1984, p.38].

Desta forma, a motivação intrínseca refere-se à causas internas de cada um, ou seja, não há razões fora da autonomia pessoal. Apesar de qualquer pessoa se acreditar racional e consciente nas próprias decisões, muitas das decisões tomadas sofrem por influência externa, sendo qualificada como extrínseca. Nesse caso, dentro desta pesquisa, o fator de influência extrínseco entraria nas condições de visão sobre os professores, disciplinas ofertadas no curso, participação de projetos, etc. No fator intrínseco, é considerável questões internas como curiosidade, experiência, etc.

\section{Resultados e Discussão}


Ao ter contato com as respostas ${ }^{5}$ durante a pré-análise, em resposta a pergunta um, sete discentes foram de LCC e sete de BSI, representando o percentual de 50\% para as respostas de cada curso. Desta forma, o quantitativo por período, relativo a pergunta número dois foi: uma representante do $1^{\circ}, 4^{\circ}, 8^{\circ}$ e $9^{\circ}$ período; duas representantes do $5^{\circ}$ período, assim como do $\mathrm{P}+$ (representa discente que ultrapassa o prazo de conclusão); três representantes do $3^{\circ}$ e $6^{\circ}$ período; e para o $2^{\circ}$ e $7^{\circ}$ período não houveram respostas para serem representadas. Logo após, houve uma sintetização das respostas da pergunta de número três, onde ficou compreendida que a motivação das meninas para a área de TI é gerada pela curiosidade pessoal, referências e por ser uma área profissional ampla e auspiciosa.

Em resposta à pergunta número quatro, as subáreas indicadas como mais desconhecidas pelas participantes (opções "Desconheço e tenho interesse em estudar" e "Desconheço e NÃO tenho interesse em estudar") foram: Biologia Computacional e Geoinformática (92,8\%), Computação Aplicada à Saúde e Computação Musical (71,4\%), Métodos Formais (64,3\%), Sistemas Colaborativos e Sistemas Tolerante à Falhas $(57,1 \%)$, seguindo ainda com Inteligência Computacional e Processamento de Linguagem Natural (50\%).

As subáreas que as participantes indicaram como mais conhecidas, ou seja, conhecer de alguma forma, foram (opções "Conheço e tenho interesse em estudar", "Conheço e NÃO tenho interesse em estudar"): Com 78,6\% Arquitetura de Computadores e Banco de Dados, respectivamente. Engenharia de Software e Linguagem de Programação (71,4\%). Na sequência vem Inteligência Artificial, Jogos e Entretenimento Digital, Realidade Virtual, Redes de Computadores e Segurança da Informação $(64,3 \%)$.

As subáreas informadas como mais interessantes (opções "Desconheço e tenho interesse em estudar" e "Conheço e tenho interesse em estudar") foram: Inteligência Artificial e Sistemas Multimídia e Web (85,7\%), depois vêm Banco de Dados (78,6\%); Engenharia de Software $(71,4 \%)$, Jogos e Entretenimento Digital $(71,4 \%)$ e Realidade virtual $(71,4 \%)$.

Já as subáreas menos interessantes (opções "Desconheço e NÃO tenho interesse" e "Conheço e NÃO tenho interesse em estudar") segundo as participantes são: Geoinformática (78,6\%), Algoritmos, Combinatória e Otimização; Métodos Formais, ambas com 57,1\% das respostas. Arquitetura de Computadores e Processamento de Alto Desempenho (50\%).

As subáreas mais conhecidas e interessantes, de acordo com as respostas foram: Inteligência Artificial e Linguagens de Programação com 64,3\%. Em seguida, Banco de Dados, Engenharia de Software, Redes de Computadores e Segurança da Informação, todas com 57,1\% das respostas. As subáreas mais desconhecidas e menos interessantes são Geoinformática $(78,6 \%)$ e Métodos Formais $(57,1 \%)$.

Para representar visualmente, foi desenvolvido o Gráfico 1 com o propósito de maior assimilação dos resultados.

\footnotetext{
${ }^{5}$ Obtenção dos resultados e quantificação dos dados: http://abre.ai/ajo2
} 
VIII Congresso Brasileiro de Informática na Educação (CBIE 2019)

Anais dos Workshops do VIII Congresso Brasileiro de Informática na Educação (WCBIE 2019)

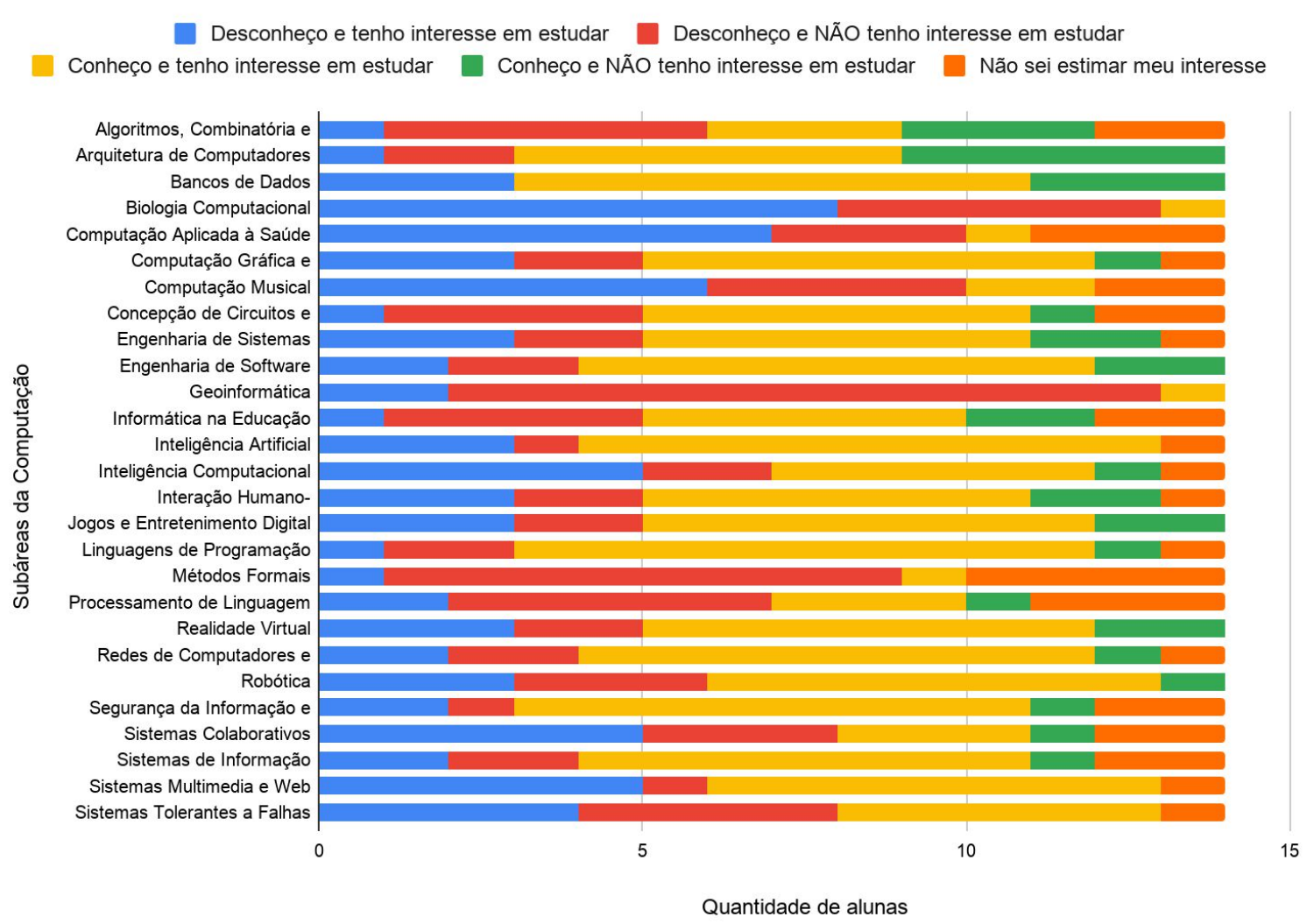

\section{Gráfico 1. Resultados}

Fazendo uma comparação com os resultados dos trabalhos relacionados, há uma relação perceptível no estudo de Figueiredo [et. al. 2017] quando mostra a influência da mídia e do lúdico entre discentes do ensino médio, e neste presente trabalho quando verificamos a influência da estrutura do curso em discentes graduandas, fazendo alusão ao que destacamos na motivação extrínseca. Já as subáreas nas quais existem mulheres de destaque atuando, conforme o estudo de Duarte [et. al. 2019], não possui penetração significativa junto às discentes do nosso estudo, o que reforça o argumento no qual as subáreas do trabalho relacionado não estão em evidência quanto a atual estrutura e dinâmica de funcionamento dos cursos sob nossa análise.

Vale ressaltar que a subárea Informática na Educação encontra-se com 42,9\% de interesse, correspondendo a seis respostas em relação ao total, o que implica em um nível de interesse baixo em relação às outras subáreas. Tendo em vista que $50 \%$ das discentes que responderam são de licenciatura, demonstrando pouco interesse e atratividade pela subárea. Não se pode entender a real causa deste resultado liminar, porém surge a hipótese de o curso não construir na formação do discente características como didática e metodologias de ensino da computação, assim como fomentar e desenvolver tecnologias na educação ou práticas de ensino de computação durante o curso. Ações estas, que ficam restritas à projetos e processos seletivos, impossibilitando 
VIII Congresso Brasileiro de Informática na Educação (CBIE 2019)

Anais dos Workshops do VIII Congresso Brasileiro de Informática na Educação (WCBIE 2019)

o futuro educador ter o conhecimento mais prático e relacionado à docência durante sua formação, prendendo-os aos conceitos mais técnicos e teóricos da grade curricular.

Cumprindo o último processo da metodologia, com base nas respostas das discentes, elaboramos na Tabela 1 informações a respeito da percepção resumida das Grandes Áreas (GAs). A tabela mencionada encontra-se na sequência:

\begin{tabular}{|c|c|}
\hline Grande Área (GA) & Percepção \\
\hline GA 1. Sistemas Computacionais & $\begin{array}{c}\text { Há poucas subáreas conhecidas } \\
\text { e com interesse de estudo. }\end{array}$ \\
\hline GA 2. Sistemas de Software & $\begin{array}{c}\text { Existem algumas subáreas } \\
\text { conhecidas e com interesse de } \\
\text { estudo. }\end{array}$ \\
\hline $\begin{array}{c}\text { GA 3. Técnicas e Tecnologias de } \\
\text { Computação }\end{array}$ & $\begin{array}{c}\text { Há poucas subáreas conhecidas } \\
\text { e há mais subáreas com } \\
\text { interesse do que sem interesse } \\
\text { de estudo. }\end{array}$ \\
\hline $\begin{array}{c}\text { GA 4. Aplicações da } \\
\text { Computação }\end{array}$ & $\begin{array}{c}\text { Encontra-se nas menos } \\
\text { conhecidas e há mais subáreas } \\
\text { com interesse do que sem } \\
\text { interesse de estudo }\end{array}$ \\
\hline $\begin{array}{c}\text { GA 5. Gestão de Dados e de } \\
\text { Informações }\end{array}$ & $\begin{array}{c}\text { Está entre as mais conhecidas e } \\
\text { interessantes de estudo. }\end{array}$ \\
\hline
\end{tabular}

Tabela 1. Percepção por GA

Em relação à última pergunta do formulário, as mulheres ao serem questionadas sobre a motivação para a escolha de tais subáreas, percebemos que houveram equivalências entre as motivações. Do total de relatos, cerca de $14 \%$ se mantiveram imparciais, ou seja, considerando tanto as condições internas quanto externas. Das outras respostas, $36 \%$ são motivadas por fatores internos. E do valor restante (50\%), classificado como maioria, descreveram serem motivadas por condições externas, guiadas dentro da universidade através de professores, disciplinas, palestras, projetos de extensão e pesquisas, ou seja, o conhecimento das discentes está diretamente ligado a estrutura dos cursos.

\section{Considerações Finais}

Com este trabalho, foram apresentados os resultados de uma pesquisa com a compreensão das discentes de TI do campus de interior da Universidade Federal da Paraíba, a respeito do conhecimento, interesse e motivação sobre as subáreas da computação. Embora poucas respostas tenham sido exploradas, pelo fato do número de participantes ter sido estatisticamente baixo, no decorrer da análise aplicada [Bardin 2016], compreendeu-se que as meninas se identificaram mais com as subáreas da GA 3. Técnicas e Tecnologias de Computação.

Interessante destacar que apesar do curso de LCC possuir evidentemente habilitação em licenciatura e envolver os aspectos tecnológicos na educação, o interesse e conhecimento das discentes com a subárea Informática na Educação demonstrou-se em declínio comparado às outras subáreas e não aparece, de forma significativa, como 
fator de atratividade ou repulsa. De acordo com a análise detalhada dos dados, esse interesse é difuso tanto no bacharelado quanto na licenciatura, trazendo ao entendimento que a habilitação do curso encontra-se como fator secundário em relação ao contexto acadêmico. Incluindo o fato da formação de futuros educadores para o ensino de computação e informática se encontrar retida, sendo assim, as discentes demonstram interesse pelas áreas em si. Surge, então, a possibilidade de entender em outra pesquisa o porquê a subárea não está listada tampouco como "área de interesse".

Enfatizamos também que as mulheres se sentem mais motivadas extrinsecamente, através do ambiente acadêmico como um todo, do que intrinsecamente. Isto significa, que os elementos do ambiente no qual as discentes estão inseridas influenciam nas escolhas das subáreas de conhecimento e interesse. Com isso, levanta-se a questão: se esses fatores geram grande influência na tomada de decisão pela escolha de determinadas áreas, por que os mesmos não conseguem produzir interesse e/ou motivação pela área que envolve informática na educação?

Em relação a importância deste estudo, convém ressaltar que os resultados desta pesquisa se caracterizam como uma análise preliminar e embora tenha demonstrado qualidades satisfatórias das orientações motivacionais das mulheres no contexto acadêmico, seria bastante conveniente a ampliação do mesmo para que os dados da análise exploratória possam ser confirmados por meio de outras respostas. Nesse ponto, também é importante pesquisar futuramente se as respostas dos meninos seriam diferentes ou se estariam próximas, sabendo os indícios implícitos e explícitos.

Salienta-se ainda, que no campus da universidade há um projeto voltado às mulheres, nomeado It Girls ${ }^{6}$, que tem como objetivo motivar a continuidade das discentes ingressantes, promover igualdade de gênero e gerar conscientização dos discentes e na comunidade [Dantas et. al. 2016]. O projeto conta com algumas ações onde é válido citar o Chá da Tarde, uma rede de apoio que é promovido encontros de mulheres para tratar de assuntos sérios, mas sem perder o instinto feminino [Dantas and Figueiredo 2019]. Neste aspecto, é sugestivo que para trabalhos futuros, o projeto fomente estudos a respeito das subáreas da computação, visando a isonomia do conhecimento geral das mulheres, abrangência de suas perspectivas, e possivelmente a dirimição na fuga do gênero nos cursos de LCC e BSI no campus.

\section{Referências}

Andrade, R. (2019) “A retomada do espaço da mulher na computação". Revista Pesquisa. Disponível em: https://revistapesquisa.fapesp.br/2019/05/10/a-retomada-do -espaco-da-mulher-na-computacao/. Acesso: 26 de outubro de 2019.

Bardin, Laurence. (2016) “Análise de conteúdo”, São Paulo: Edições 70.

Bergamini, C. W. (2003) "Motivação: uma viagem ao centro do conceito.", GV Executivo, 1(2), 63-67.

\footnotetext{
${ }^{6}$ https://itgirls.dcx.ufpb.br/
} 
VIII Congresso Brasileiro de Informática na Educação (CBIE 2019)

Anais dos Workshops do VIII Congresso Brasileiro de Informática na Educação (WCBIE 2019)

Dantas, V., \& Figueiredo, R. (2018) "Chá da tarde: criando uma rede de apoio entre as discentes de cursos de Computação.", In Anais do XII Women in Information Technology. Porto Alegre: SBC.

Dantas, V., Figueiredo, R., Souza, G., Nascimento, R. R., Nascimento, A. C., Martins, B. (2016) "Um Estudo Inicial Sobre As Alunas Ingressantes no Curso de Licenciatura em Ciência da Computação da Universidade Federal da Paraíba.”, In: $10^{\circ}$ WIT - Women in Information Technology, Porto Alegre: SBC.

Duarte, B., Moura, A., \& Moro, M. (2019). "Mulheres na Computação: Análises por Sub-Áreas". In Anais do XIII Women in Information Technology (pp. 174-178). SBC.

Figueiredo, K. S., Vitorassi, R., Monteiro, E., \& Carneiro, S O. (2017). "Percepções de alunas de Ensino Médio sobre as subáreas da Computação". In $11^{\circ}$ Women in Information Technology (WIT 2017) (Vol. 11, No. 1/2017). SBC.

Lima, Michelle P. (2013). "As mulheres na Ciência da Computação". Revista Estudos Feministas, 21(3), 793-816. https://dx.doi.org/10.1590/S0104-026X2013000300003

Medeiros, C. B. (2011) “Computação: ou terceiro pilar”. Revista USP, (89), 134-147. http://rusp.scielo.br/scielo.php?script=sci_arttext\&pid=S0103-99892011000200010 $\& \operatorname{lng}=$ en\&tlng=en. Acesso em 29 de setembro de 2019.

Tuzzo, S. A., Braga C. F. (2016) "O processo de triangulação da pesquisa qualitativa: o metafenômeno como gênese", Revista Pesquisa Qualitativa. São Paulo (SP), v.4, n.5, p.140-158.

SBC (2019) "Sociedade Brasileira de Computação - Comissões Especiais", Página da Web, disponível em: http://www.sbc.org.br/403-comissoes-especiais. Acesso: 29 de setembro de 2019.

SBIE - Sociedade Brasileira de Inteligência Emocional (2017) "Entenda a diferença entre motivação intrínseca e extrínseca". Página da Web, disponível em: https://www.

sbie.com.br/blog/entenda-diferenca-entre-motivacao-intrinseca-e-extrinseca/. Acesso: 29 de setembro de 2019.

Schwartz, J.; Casagrande, L. S.; Leszczynski, Sonia A. C.; Carvalho, M. G. (2006) "Mulheres na informática: quais foram as pioneiras ?" Cadernos Pagu, (27), 255-278. https://dx.doi.org/10.1590/S0104-83332006000200010

Witter, G. P., Lomonaco, J. F. B. (1984) "Psicologia da Aprendizagem”. São Paulo. Editora Pedagógica e Universitária Ltda. 